\title{
Dual modulation of the T-cell receptor-activated signal transduction pathway by morphine in human T lymphocytes.
}

\section{$\operatorname{AUTHOR}(\mathrm{S})$ :}

Mizota, Toshiyuki; Tsujikawa, Hiroshi; Shoda, Takehiro; Fukuda, Kazuhiko

\section{CITATION:}

Mizota, Toshiyuki ...[et al]. Dual modulation of the T-cell receptor-activated signal

transduction pathway by morphine in human T lymphocytes.. Journal of anesthesia 2013 , 27(1): 80-87

\section{ISSUE DATE:}

2013-02

URL:

http://hdl.handle.net/2433/172077

\section{RIGHT:}

The final publication is available at www.springerlink.com; この論文は 出版社版でありません。引用の際には出版社版をご確認ご利用くださ $\iota_{\circ}$; This is not the published version. Please cite only the published version. 
Dual modulation of the $\mathrm{T}$ cell receptor-activated signal transduction pathway by morphine in human T lymphocytes

Toshiyuki Mizota, M.D., ${ }^{*}$ Hiroshi Tsujikawa, M.D., Ph.D., Takehiro Shoda, M.D., Ph.D., Kazuhiko Fukuda, M.D., Ph.D.

Department of Anaesthesia, Kyoto University Hospital, Kyoto, Japan

Corresponding author: Toshiyuki Mizota

Mailing address: Department of Anesthesia, Kyoto University Hospital, 54 ShogoinKawaracho, Sakyo-Ku, Kyoto 606-8507, Japan

Tel: $+81-75-751-3433$

Fax: $+81-75-752-3259$

e-mail: mizota@kuhp.kyoto-u.ac.jp

Key words: morphine, ERK1/2, nuclear factor- $\kappa \mathrm{B}$, opioid-induced immunomodulation

Word count: 3,211

Number of tables: 0

Number of figures: 6 


\section{Abstract}

Purpose: In this study, we aimed to investigate the effect of morphine on activation of extracellular signal-regulated kinase (ERK) and nuclear factor- $\kappa \mathrm{B}(\mathrm{NF}-\kappa \mathrm{B})$, both of which play crucial roles in $\mathrm{T}$ cell activation.

Methods: Human CD3+ T cells and Jurkat T cells were stimulated by anti-CD3 antibody or phorbol 12-myristate 13-acetate plus ionomycin with or without 24-h pretreatment with morphine. Activation of ERK was assessed by immunoblot analysis of phosphorylated ERK. Activation of the NF- $\mathrm{BB}$ signaling pathway was examined by analyzing nuclear factor of kappa light polypeptide gene enhancer in B-cells inhibitor, alpha $(\mathrm{I} \kappa \mathrm{B} \alpha)$ phosphorylation using immunoblotting, and interleukin-2 (IL-2) gene expression using quantitative real-time reverse-transcriptase polymerase chain reaction.

Results: Morphine pretreatment enhanced ERK phosphorylation, but inhibited IкB $\alpha$ phosphorylation and IL-2 gene expression in activated T cells. The effects of morphine on ERK phosphorylation and IL-2 gene expression were not antagonized by naloxone. We detected $\kappa$-opioid receptor transcript in T cells, but U50,488, a $\kappa$-receptor-selective agonist, did not enhance ERK phosphorylation.

Conclusion: Morphine enhances ERK signaling, whereas it inhibits NF- $\kappa \mathrm{B}$ signaling in activated human $\mathrm{T}$ cells. These effects of morphine are unlikely to be mediated by known opioid receptors. 
Introduction

Morphine is one of the opioid analgesic drugs which play important roles in perioperative settings. Opioids reduce preoperative anxiety, decrease somatic and autonomic responses to airway manipulations, improve intraoperative hemodynamic stability, lower requirements for anesthetics, and provide postoperative analgesia [1]. On the other hand, morphine administration results in severe immune suppression, and thus may pose a significant risk factor for opportunistic infections such as tuberculosis, human immunodeficiency virus infection, and pneumonia [2,3]. Although many studies have provided overwhelming evidence for morphine-induced changes in immune parameters [3], the mechanisms by which these effects are mediated are still to be conclusively determined. Two major mechanisms have been implicated; a direct mechanism in which opioids bind to receptors on immune cells and directly modulate the function of these cells [4-7], and an indirect mechanism in which opioids bind to opioid receptors in the central nervous system, causing the release of catecholamines and steroids, which then affect the functioning of immune cells $[8,9]$.

Chronic treatment with morphine has been shown to affect the function of T cells, which play a crucial role in the defense against nosocomial infection [10]. Chronic morphine treatment results in a decrease in $\mathrm{CD} 4+/ \mathrm{CD} 8+$ population [11], reduction in proliferative response of T cells [12], and induction of differentiation into type 2 helper T cells (Th2) [13]. It is well known that the T cell receptor (TCR) engagement induces activation of multiple signal transduction pathways, including the mitogen-activated protein-kinase (MAPK) pathways and nuclear factor- $\kappa \mathrm{B}(\mathrm{NF}-\kappa \mathrm{B})$ pathway. A possible target for modulation by 
morphine among MAPK pathways might be the extracellular signal-regulated kinase (ERK), which is activated rapidly through threonine and tyrosine phosphorylation following TCR engagement. ERK is an important participant in the regulation of cell proliferation and differentiation by phosphorylation of a number of intracellular proteins, including transcription factors and protein kinases [14]. In T cells, ERK plays crucial roles in T-cell maturation and differentiation $[15,16]$. Modulation of the ERK signaling pathway may cause changes in $\mathrm{T}$ cell functions, and therefore susceptibility to infection. NF- $\kappa \mathrm{B}$ is activated through phosphorylation and degradation of nuclear factor of kappa light polypeptide gene enhancer in B-cells inhibitor, alpha $(\mathrm{I} \kappa \mathrm{B} \alpha)$ following TCR engagement, and induces transcription from many inflammatory genes, including those encoding inflammatory cytokines and regulatory chemokines [17]. Although modulation of ERK and NF- $\kappa \mathrm{B}$ signaling pathways by morphine has been demonstrated in activated murine T cells [18], the effect of morphine on these signal transduction pathways in activated human T cells is not known. In this investigation, we aimed to determine the direct effect of morphine on ERK

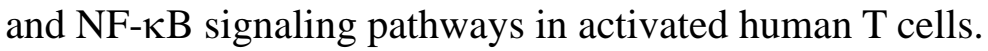


Materials and Methods

\section{Materials}

The human leukemic T cell line, Jurkat, was obtained from American Type Culture Collection (Manassas, VA). The culture medium and other cell culture products were obtained from Sigma (St. Louis, MO). Human placenta total RNA was purchased from Clontech (Mountain View, CA). Morphine hydrochloride was purchased from Takeda (Osaka, Japan). Phorbol 12-myristate 13-acetate (PMA), ionomycin, naloxone hydrochloride, and U50,488 were purchased from Sigma. HIT3a (anti-human CD3 monoclonal antibody) was purchased from BD Biosciences (Franklin Lakes, NJ). Mouse monoclonal antibody

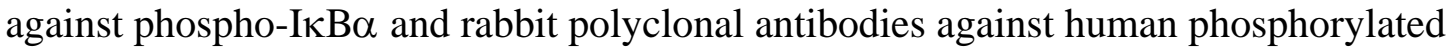
ERK1/2 and ERK1/2 were purchased from Cell Signaling Technology (Danvers, MA). Rabbit polyclonal antibody against $\beta$-actin was purchased from BioLegend (San Diego, CA). Horseradish peroxidase-conjugated sheep anti-mouse and donkey anti-rabbit IgGs were purchased from GE Healthcare Bioscience (Uppsala, Sweden).

\section{Cell Culture and Treatment}

Blood was collected from healthy adult volunteers from Kyoto University after informed consent was obtained, and the protocols were reviewed and approved by the appropriate Investigative Review Boards. Peripheral blood mononuclear cells were isolated by density-gradient centrifugation using Ficoll-Paque ${ }^{\mathrm{TM}}$ PLUS (GE healthcare Bioscience), and CD3+ T cells were subsequently purified using a Pan T Cell Isolation Kit II (Miltenyi 
Biotec, Bergisch Gladbach, Germany) following the manufacturer's protocol. Purification of CD3+ T cells was conducted using autoMACS (Miltenyi Biotec). CD3+ T cells and Jurkat T cells were cultured in RPMI1640 medium supplemented with $2 \mathrm{mM} \mathrm{L-glutamine,} 10 \mathrm{mM}$ HEPES, $1.5 \mathrm{~g} / \mathrm{L}$ sodium bicarbonate, $4.5 \mathrm{~g} / \mathrm{L}$ glucose, $1 \mathrm{mM}$ sodium pyruvate, $10 \%$ fetal bovine serum, and $1 \%$ penicillin/streptomycin. Cells were incubated at $37{ }^{\circ} \mathrm{C}$ in a $5 \% \mathrm{CO}_{2}$ atmosphere.

Isolated human $\mathrm{CD} 3+\mathrm{T}$ cells $\left(10^{7}\right.$ cells each) or Jurkat $\mathrm{T}$ cells $\left(10^{6}\right.$ cells each) were pretreated with morphine or U50,488 for $24 \mathrm{~h}$. When indicated, cells were treated with naloxone 15 min prior to morphine. After the pretreatment, cells were washed with phosphate buffered saline and resuspended in $1 \mathrm{ml}$ of culture medium. Cells were subsequently stimulated with HIT3a $(2 \mu \mathrm{g} / \mathrm{ml})$ or PMA $(20 \mathrm{ng} / \mathrm{ml})$ plus ionomycin (100 $\mathrm{ng} / \mathrm{ml}$ ) for indicated times.

\section{Immunoblot Analysis}

Cells were collected by 30 -sec centrifugation at $4{ }^{\circ} \mathrm{C}$ and $4,000 \mathrm{~g}$ and resuspended in NP40 lysis buffer [1\% NP40, $150 \mathrm{mM} \mathrm{NaCl}, 50 \mathrm{mM}$ Tris-Cl (pH 7.5), Halt ${ }^{\mathrm{TM}}$ Protease Inhibitor Cocktail (Pierce Biotechnology, Inc., Rockford, IL), and phosphatase inhibitor cocktail (Nacalai Tesque, Inc., Kyoto, Japan)]. After 30-min incubation on ice, whole-cell lysates were prepared by 5 -min centrifugation at $4{ }^{\circ} \mathrm{C}$ and $15,000 \mathrm{~g}$. In each experiment, samples were used at equal amounts of total protein, which ranged from 30 to $50 \mu \mathrm{g}$. Proteins were separated by $10 \%$ sodium-dodecyl-sulfate polyacrylamide gel electrophoresis and electrophoretically transferred to polyvinylidene difluoride membranes. Membranes 
were incubated with primary antibodies for phosphorylated ERK, phosphorylated $\mathrm{I} \kappa \mathrm{B} \alpha$, total ERK, or $\beta$-actin at 1:1,000 dilution followed by horseradish peroxidase-conjugated secondary antibodies at 1:20,000 dilution. To quantify phosphorylated ERK or I $\mathrm{B} \alpha$, total ERK or $\beta$ actin was assessed by imunoblot analysis using the same membrane after stripping.

Membranes were stripped by incubation in stripping buffer (2\% sodium dodecyl sulfate, 62.5 $\mathrm{mM}$ Tris- $\mathrm{HCl} \mathrm{pH} 6.8,0.8 \% \beta$-mercaptoethanol) at $50{ }^{\circ} \mathrm{C}$ for $30 \mathrm{~min}$ and rinsed with Tris buffered saline containing $0.05 \%$ Tween20. Immunoreactive bands were visualized using chemiluminescence (ECL plus, GE healthcare Bioscience). The quantity of the immunoreactive bands was determined by densitometry using ImageJ (provided by National Institutes of Health). Phosphorylated ERK or I $\mathrm{BB} \alpha$ levels in PMA/ionomycin- or HIT3astimulated cells without pretreatment were defined as controls, and the amount of phosphorylated ERK or I $\kappa \mathrm{B} \alpha$ was expressed as a percentage of the control.

\section{Total RNA Isolation}

After collecting cells by 30 -sec centrifugation at $4{ }^{\circ} \mathrm{C}$ and $4,000 \mathrm{~g}$, total RNA was isolated using an illustra RNAspin Mini RNA isolation Kit (GE Healthcare Bioscience) according to the manufacturer's instructions and dissolved in diethyl pyrocarbonate-treated water. The RNA was quantified by A260 measurement.

Reverse-transcriptase Polymerase-chain-reaction (RT-PCR), Cloning of PCR Products, and DNA Sequence Analysis

Complementary DNA (cDNA) was synthesized from $1 \mu \mathrm{g}$ total RNA using a SuperScriptIII First-Strand Synthesis System for RT-PCR (Invitrogen) according to the 
system protocol. One fiftieth of the synthesized cDNA was amplified using the Platinum ${ }^{\circledR}$ Taq DNA polymerase HighFidelity (Invitrogen). The amplification was performed in a GeneAmp® PCR System 9700 (Applied Biosystems, Foster City, CA). The nucleotide sequences of the primers for $\kappa$ opioid receptor were 5 '-

AAAGTCAGGGAAGACGTCGATGTC -3' and 5'-

GAATGGGATTCAGGCTACTGTTGG -3' (described previously [19]). After an initial 3min incubation at $95^{\circ} \mathrm{C}$, cDNA was amplified for 40 cycles $\left(95^{\circ} \mathrm{C}\right.$ for $20 \mathrm{sec}, 59^{\circ} \mathrm{C}$ for 30 sec, $72{ }^{\circ} \mathrm{C}$ for $\left.30 \mathrm{sec}\right)$. PCR products were separated on $1.5 \%$ agarose gel containing 0.1 $\mu \mathrm{g} / \mathrm{ml}$ ethidium bromide and photographed under ultra-violet illumination.

After separation on agarose gel, the main band was excised by TaKaRa RECOCHIP (Takara Bio inc., Otsu, Japan). The PCR products were cloned into pGEM®-T Easy vector (Promega, Madison, WI ) and sequenced using a Big Dye Terminator Sequencing Kit (PerkinElmer, Foster City, CA) and an ABI 377 sequencer (Applied Biosystems). Sequence data was analyzed with Sequencher 3.1 (Gene Codes, Ann Arbor, MA).

\section{Quantitative Real-Time RT-PCR}

For quantitative real-time RT-PCR, $100 \mathrm{ng}$ of total RNA was used as a template. Firststrand synthesis and real-time PCR reaction was performed using a QuantiTect SYBR Green PCR Kit ${ }^{\mathrm{TM}}$ (Qiagen Inc., Germantown, MD) following a protocol provided by the company. PCR reaction and detection was performed using an Applied Biosystems 7300 real time PCR system. PCR primers were purchased from Qiagen Inc. The fold change in expression of interleukin-2 (IL-2) mRNA relative to glyceraldehyde-3-phosphate dehydrogenase (GAPDH) was calculated. 
Statistical Analysis

Results are expressed as percentages of the controls in means and standard deviations. In all experiments, the normality of the data was tested using Shapiro-Wilks test and the null hypothesis was not rejected. Comparisons between two groups were performed with Student's t-test. Multiple comparisons were performed with one-way ANOVA followed by Student-Newman-Keuls test. $\quad \mathrm{P}<0.05$ was considered statistically significant. 
Results

Effect of Morphine on ERK Phosphorylation in Stimulated CD3+ T Cells and Jurkat T Cells

Stimulation with anti-CD3 antibody for 5 min induced ERK phosphorylation in CD3+ T cells. Pretreatment of CD3+ T cells with morphine significantly enhanced ERK phosphorylation induced by anti-CD3 antibody (Fig. 1A). Similarly, in Jurkat T cells, stimulation with anti-CD3 antibody for 5 min induced ERK phosphorylation, and morphine pretreatment enhanced ERK phosphorylation (Fig. 1B). In contrast, 24-h morphine treatment alone did not induce ERK phosphorylation in Jurkat T cells (Fig. 1B).

Next we examined the effect of morphine on ERK phosphorylation induced by PMA plus ionomycin (PMA/Io). Stimulation with PMA/Io mimics the T-cell-receptor-induced T cell activation by directly activating protein kinase $\mathrm{C}(\mathrm{PKC})$ and increasing the intracellular calcium concentration. In PMA/Io-stimulated Jurkat T cells, the band of phosphorylated ERK appeared within $5 \mathrm{~min}$ and lasted for more than $30 \mathrm{~min}$ (Fig. 2A). Morphine pretreatment for $24 \mathrm{~h}$ enhanced ERK phosphorylation induced by PMA/Io, whereas $24 \mathrm{~h}$ morphine treatment alone did not induce ERK phosphorylation (Fig. 2A). To determine the dependence of ERK signaling enhancement on morphine concentration, we pretreated Jurkat T cells with different concentrations of morphine and subsequently stimulated them with PMA/Io. Although $10 \mathrm{nM}$ of morphine did not have a significant effect, $1 \mu \mathrm{M}$ was sufficient to enhance ERK phosphorylation (Fig. 2B).

We previously reported that opioid receptors expressed in cultured cells activate ERK [20]. It was also reported that morphine induces ERK phosphorylation in the human 
lymphocytic cell line, CEMx174 [21]. In the present study, ERK phosphorylation was not detectable in Jurkat $\mathrm{T}$ cells treated with morphine for $24 \mathrm{~h}$ (Fig. 1B and 2A). However, these results cannot exclude morphine-induced ERK phosphorylation, because ERK phosphorylation mediated by opioid receptors peaks within 15 min [20]. To determine whether morphine by itself induces ERK phosphorylation, we treated Jurkat T cells with 100 $\mu \mathrm{M}$ morphine for 5 to $60 \mathrm{~min}$, but did not detect any ERK phosphorylation (Fig. 3).

Opioid Receptors are not Involved in the Effect of Morphine on ERK Signaling in Activated T Cells

To clarify whether the effect of morphine on the ERK signaling pathway is mediated by opioid receptors, we tested the effect of naloxone, which can inhibit all types of the opioid receptor, on the enhancement of ERK phosphorylation by morphine. Fig. 4A shows that enhancement of PMA/Io-induced ERK phosphorylation by $1 \mu \mathrm{M}$ morphine was not significantly suppressed by $10 \mu \mathrm{M}$ naloxone.

Opioid receptors are classified into three types, $\mu, \delta$, and $\kappa(\mathrm{MOR}, \mathrm{DOR}$ and KOR, respectively). To clarify whether Jurkat T cells express these types of opioid receptors, we examined mRNA expression of these receptors using RT-PCR. Although transcripts for MOR and DOR could not be detected (data not shown), we detected KOR transcript in Jurkat T cells (Fig. 4B). The nucleotide sequence of the PCR product from Jurkat $\mathrm{T}$ cells showed $100 \%$ homology with that from human placenta and the cDNA sequence of KOR from human brain (GenBank accession no. L37362) (data not shown). To determine whether KOR mediate the enhancement of ERK phosphorylation in activated T cells, we examined the 
effect of U50,488, a א-specific agonist, on ERK phosphorylation. Pretreatment of Jurkat T cells with U50,488 had no effect on PMA/Io-induced ERK phosphorylation (Fig. 4C).

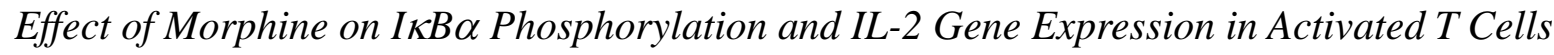

Activation of TCR leads to activation of not only ERK but also NF-אB [22]. TCR stimulation leads to activation of an IкB kinase (IKK) complex through diacylglycerol (DAG) production followed by activation of PKC $\theta$. Activated IKK complex in turn induces phosphorylation and degradation of $\mathrm{I} \kappa \mathrm{B} \alpha$, resulting in $\mathrm{NF}-\kappa \mathrm{B}$ activation. Inhibition of NF$\kappa \mathrm{B}$ activation by morphine has been demonstrated in murine $\mathrm{T}$ cells [18], but in human $\mathrm{T}$ cells the effect of morphine on the NF-א B pathway is not known.

To test the effect of morphine on signal transduction through the NF- $\kappa$ B pathway in activated $\mathrm{T}$ cells, we investigated the effect of morphine on $\mathrm{I} \kappa \mathrm{B} \alpha$ phosphorylation. In preliminary experiments, we examined the time course of $\mathrm{I} \kappa \mathrm{B} \alpha$ phosphorylation induced by PMA/Io. After PMA/Io stimulation, the band of phosphorylated $\mathrm{I} \kappa \mathrm{B} \alpha$ appeared at $5 \mathrm{~min}$, peaked at $15 \mathrm{~min}$, and disappeared at $30 \mathrm{~min}$ (data not shown). Accordingly, we thereafter stimulated cells for 15 min to examine the effect of morphine on IкB $\alpha$ phosphorylation. As shown in Fig. 5A, pretreatment of Jurkat $\mathrm{T}$ cells with morphine significantly inhibited PMA/Io-induced I $\mathrm{B} \alpha$ phosphorylation.

IL-2 is a pivotal cytokine involved in T cell regulation, proliferation, and host defense mechanisms [23], and its expression is regulated by multiple transcription factors including NF- $\kappa \mathrm{B}$ [24]. To determine the effect of morphine on IL-2 production in activated T cells, we pretreated Jurkat $\mathrm{T}$ cells with morphine and examined its effect on IL-2 gene expression after 
stimulation. IL-2 gene expression induced by PMA/Io was suppressed by morphine in a dose-dependent manner (Fig. 5B). Naloxone did not antagonize the inhibitory effect of morphine on IL-2 expression (Fig. 5C). 


\section{Discussion}

In this investigation, we demonstrated that pretreatment with morphine enhances ERK phosphorylation, but suppresses I $\mathrm{B} B \alpha$ phosphorylation and IL-2 gene expression in activated human $\mathrm{T}$ cells. These responses were not significantly antagonized by naloxone. To our knowledge, this is the first report of dual modulation of the $\mathrm{T}$ cell receptor-activated signal transduction pathway by morphine in human T lymphocytes.

While Chuang et al. demonstrated that morphine induces ERK phosphorylation in a human lymphocytic cell line, CEMx174 [21], morphine by itself did not induce ERK phosphorylation in Jurkat $\mathrm{T}$ cells in this study. This apparent inconsistency might be explained by the absence of functional opioid receptors or an ERK activation pathway linked with the opioid receptors in Jurkat T cells. The lack of ERK phosphorylation following stimulation by morphine for 5-60 min or $24 \mathrm{~h}$ suggests that the potentiating effect of morphine on ERK phosphorylation in activated T cells is not through direct activation of the ERK signaling pathway but by indirect modulation of signal transduction. TCR stimulation results in activation of ERK through two different pathways [25] (Fig. 6). One pathway is through Growth factor receptor-bound protein 2 (Grb2) and Son of sevenless (SOS), which is analogous to what has been observed for Ras-mediated ERK activation triggered by stimulation of growth factor receptors [26]. The other pathway is through activation of Ras guanyl nucleotide-releasing protein (RasGRP) by DAG. Although the mechanism by which DAG activates RasGRP remains to be established, involvement of a novel PKC subfamily $(\operatorname{PKC} \delta, \varepsilon, \eta, \theta)$ is suggested. We have demonstrated that morphine enhances ERK 
phosphorylation induced by stimulation with PMA/Io as well as anti-CD3 antibody. This result suggests that the potentiating effect of morphine on ERK phosphorylation is through modulation of the signaling pathway downstream of DAG, because PMA, a synthetic DAG analogue, activates ERK by PKC activation.

We have demonstrated that morphine inhibits IL-2 gene expression in activated T cells. Since IL-2 plays a crucial role for T cell activation and proliferation [23], inhibition of IL-2 expression may at least partly explain the immunosuppression by morphine. We also showed

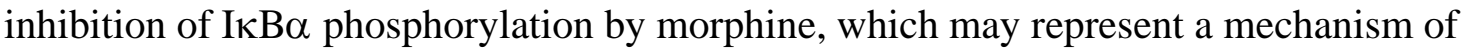
inhibition of IL-2 expression. Although the NF-кB pathway and ERK signaling pathway have a common upstream signaling pathway including DAG and PKC in T cells [27,28], morphine inhibited PMA/Io-induced IкB $\alpha$ phosphorylation, whereas it enhanced PMA/Ioinduced ERK phosphorylation. These results indicate that morphine has opposite effects on the two signal transduction pathways downstream of DAG: an inhibitory effect on the DAGPKC $\theta-N F-\kappa B$ pathway, and augmentation of the DAG-PKC-RasGRP-Ras-ERK pathway.

The enhancement of the ERK signaling pathway by morphine shown in this study may be involved in the mechanisms of morphine-induced Th2 differentiation [13], since activation of the ERK pathway is implicated in Th2 differentiation [16]. Our results seem to be inconsistent with the previous report [18] that morphine pretreatment inhibits the ERK signaling pathway in activated murine T c14-ells. It may be that the response of $\mathrm{T}$ cells to morphine differs in different animal species. On the other hand, suppression of the NF- $\mathrm{BB}$ pathway and IL-2 expression by morphine may result in reduction of the proliferative response of T-cells and immune suppression, because IL-2 is known to positively regulate T 
cell proliferation $[23,24]$. However, morphine is known to indirectly affect immune-cell functions by modulating the release of catecholamines and steroids [8,9], and whether or not morphine administration in vivo has the same effects as demonstrated in this study remains to be investigated.

We have shown that the effects of morphine on ERK phosphorylaion and IL-2 gene expression are not antagonized by naloxone. This suggests that the effect of morphine on the ERK pathway and the NF- $\kappa$ B pathway is not mediated by opioid receptors. Several studies suggest that immune cells express opioid receptors [4,5], but it is not conclusively known whether or not functional opioid receptors are expressed in human T cells. We examined gene expression of three types of opioid receptors, $\mu, \delta$ and $\kappa$, in Jurkat T cells, and detected only KOR transcript. However, U50,488, a $\kappa$ receptor-specific agonist, did not enhance ERK phosphorylation in activated T cells, suggesting that KOR does not mediate the enhancement of ERK phosphorylaion by morphine. Thus, further study of the receptor which mediates the effect of morphine on the ERK signaling pathway is required. It is interesting that the existence of naloxone-insensitive low-affinity morphine binding sites that are different from the classical opioid receptors have been reported [6].

We have demonstrated that $1 \mu \mathrm{M}$ of morphine is sufficient to enhance ERK phosphorylation in activated T cells, whereas morphine concentration as high as $100 \mu \mathrm{M}$ was necessary to suppress IL-2 expression. The plasma concentration of morphine in clinical practice ranges from 25 to $250 \mathrm{nM}[29,30]$. Morphine at these concentrations may have limited effect on ERK phosphorylation and IL-2 expression in activated T cells. However, it is reported that major surgical stress modulates the T cell-mediated immune response [31]. 
Thus, it is possible that morphine influences the alteration of $\mathrm{T}$ cell function induced by surgical stress in patients undergoing major surgery. Plasma concentration of morphine reaches up to $5 \mu \mathrm{M}$ after high-dose morphine treatment for cancer pain [32]. So it is possible that morphine influences the ERK signaling pathway and IL-2 expression during T cell activation in patients receiving high-dose morphine treatment.

In summary, we have shown that morphine enhanced ERK phosphorylation but inhibited I $\mathrm{B} \alpha$ phosphorylation and IL-2 gene expression in activated human T cells, by a mechanism which does not involve known opioid receptors. These cellular responses might be involved in the functional alteration of T cells in patients to whom high-dose morphine is administered. 
Acknowledgments

The authors wish to thank Toshiyuki Arai (Associate Professor, Department of Anaesthesia, Kyoto University Hospital) and Kohei Yamashita (Assistant Professor, Department of Hematology and Oncology, Kyoto University Hospital) for volunteer recruitment. This work was supported by Grants-in-Aid for Scientific Research from the Ministry of Health, Labour and Welfare of Japan, Tokyo, Japan. 


\section{References}

1. Ebert J, Pearson J, Gelman S, Harris C, Bradley E. Circulatory responses to laryngoscopy: the comparative effects of placebo, fentanyl and esmolol. Can J Anaesth. 1989;36:301-6.

2. Friedman H, Newton C, Klein T. Microbial infections, immunomodulation, and drugs of abuse. Clin Microbiol Rev. 2003;16:209-19.

3. Roy S, Wang J, Kelschenbach J, Koodie L, Martin J. Modulation of immune function by morphine: implications for susceptibility to infection. J Neuroimmune Pharmacol. 2006;1:7789.

4. Sharp B, Roy S, Bidlack J. Evidence for opioid receptors on cells involved in host defense and the immune system. J Neuroimmunol. 1998;83:45-56.

5. Mehrishi J, Mills I. Opiate receptors on lymphocytes and platelets in man. Clin Immunol Immunopathol. 1983;27:240-9.

6. Roy S, Ge B, Loh H, Lee N. Characterization of [3H]morphine binding to interleukin-1activated thymocytes. J Pharmacol Exp Ther. 1992;263:451-6.

7. Makman M, Dvorkin B, Stefano G. Murine macrophage cell lines contain mu 3-opiate receptors. Eur J Pharmacol. 1995;273:R5-6.

8. Bryant H, Bernton E, Kenner J, Holaday J. Role of adrenal cortical activation in the immunosuppressive effects of chronic morphine treatment. Endocrinology. 1991;128:3253-8.

9. Fecho K, Maslonek K, Dykstra L, Lysle D. Evidence for sympathetic and adrenal involvement in the immunomodulatory effects of acute morphine treatment in rats. $\mathrm{J}$ Pharmacol Exp Ther. 1996;277:633-45.

10. Slifka M, Whitton J. Clinical implications of dysregulated cytokine production. J Mol Med. 2000;78:74-80. 
11. Carr D, France C. Immune alterations in chronic morphine-treated rhesus monkeys. Adv Exp Med Biol. 1993;335:35-9.

12. Roy S, Chapin R, Cain K, Charboneau R, Ramakrishnan S, Barke R. Morphine inhibits transcriptional activation of IL-2 in mouse thymocytes. Cell Immunol. 1997;179:1-9.

13. Roy S, Balasubramanian S, Sumandeep S, Charboneau R, Wang J, Melnyk D, Beilman G, Vatassery R, Barke R. Morphine directs T cells toward T(H2) differentiation. Surgery. 2001;130:304-9.

14. Boulton TG, Nye SH, Robbins DJ, Ip NY, Radziejewska E, Morgenbesser SD, DePinho RA, Panayotatos N, Cobb MH, Yancopoulos GD. ERKs: a family of protein-serine/threonine kinases that are activated and tyrosine phosphorylated in response to insulin and NGF. Cell. 1991;65:663-75.

15. Crompton T, Gilmour K, Owen M. The MAP kinase pathway controls differentiation from double-negative to double-positive thymocyte. Cell. 1996;86:243-51.

16. Yamashita M, Kimura M, Kubo M, Shimizu C, Tada T, Perlmutter R, Nakayama T. T cell antigen receptor-mediated activation of the Ras/mitogen-activated protein kinase pathway controls interleukin 4 receptor function and type- 2 helper T cell differentiation. Proc Natl Acad Sci USA. 1999;96:1024-9.

17. Barnes P, Karin M. Nuclear factor-kappaB: a pivotal transcription factor in chronic inflammatory diseases. N Engl J Med. 1997;336:1066-71.

18. Wang J, Barke RA, Charboneau R, Loh HH, Roy S. Morphine negatively regulates interferon-gamma promoter activity in activated murine $\mathrm{T}$ cells through two distinct cyclic AMP-dependent pathways. J Biol Chem. 2003;278:37622-31.

19. Suzuki S, Chuang L, Doi R, Bidlack J, Chuang R. Kappa-opioid receptors on lymphocytes of a human lymphocytic cell line: morphine-induced up-regulation as evidenced by 
competitive RT-PCR and indirect immunofluorescence. Int Immunopharmacol. 2001;1:173342.

20. Fukuda K, Kato S, Morikawa H, Shoda T, Mori K. Functional coupling of the delta-, mu-, and kappa-opioid receptors to mitogen-activated protein kinase and arachidonate release in Chinese hamster ovary cells. J Neurochem. 1996;67:1309-16.

21. Chuang LF, Killam KF, Jr., Chuang RY. Induction and activation of mitogen-activated protein kinases of human lymphocytes as one of the signaling pathways of the immunomodulatory effects of morphine sulfate. J Biol Chem. 1997;272:26815-7.

22. Schulze-Luehrmann J, Ghosh S. Antigen-receptor signaling to nuclear factor kappa B. Immunity. 2006;25:701-15.

23. Smith KA. Interleukin-2. Curr Opin Immunol. 1992;4:271-6.

24. Jain J, Loh C, Rao A. Transcriptional regulation of the IL-2 gene. Curr Opin Immunol. $1995 ; 7: 333-42$.

25. Roose J, Mollenauer M, Gupta V, Stone J, Weiss A. A diacylglycerol-protein kinase CRasGRP1 pathway directs Ras activation upon antigen receptor stimulation of T cells. Mol Cell Biol. 2005;25:4426-41.

26. Pawson T, Saxton T. Signaling networks--do all roads lead to the same genes? Cell. 1999;97:675-8.

27. Isakov N, Altman A. Protein kinase C(theta) in T cell activation. Annu Rev Immunol. 2002;20:761-94.

28. Izquierdo M, Downward J, Graves JD, Cantrell DA. Role of protein kinase C in T-cell antigen receptor regulation of p21ras: evidence that two p21ras regulatory pathways coexist in T cells. Mol Cell Biol. 1992;12:3305-12.

29. Berkenstadt H, Segal E, Mayan H, Almog S, Rotenberg M, Perel A, Ezra D. The 
pharmacokinetics of morphine and lidocaine in critically ill patients. Intensive Care Med. $1999 ; 25: 110-2$.

30. Lotsch J, Stockmann A, Kobal G, Brune K, Waibel R, Schmidt N, Geisslinger G.

Pharmacokinetics of morphine and its glucuronides after intravenous infusion of morphine and morphine-6-glucuronide in healthy volunteers. Clin Pharmacol Ther. 1996;60:316-25. 31. Shimaoka M, Hosotsubo K, Sugimoto M, Sakaue G, Taenaka N, Yoshiya I, Kiyono H. The influence of surgical stress on T cells: enhancement of early phase lymphocyte activation. Anesth Analg. 1998;87:1431-5.

32. Wolff T, Samuelsson H, Hedner T. Morphine and morphine metabolite concentrations in cerebrospinal fluid and plasma in cancer pain patients after slow-release oral morphine administration. Pain. 1995;62:147-54. 
Figure legends

Fig. 1. Effect of morphine on ERK phosphorylation in CD3+ and Jurkat T cells stimulated with anti-CD3 antibody. CD3+ T cells (A) and Jurkat T cells (B) were incubated in the absence or presence of morphine $(100 \mu \mathrm{M})$ for $24 \mathrm{~h}$, and thereafter stimulated with anti-CD3 antibody $(2 \mu \mathrm{g} / \mathrm{ml})$ for indicated times. Phosphorylated ERK and total ERK were detected by immunoblot analysis. Extract from CD3+ T cells stimulated with PMA/Io for 5 min was used for positive control. The upper and lower band in total ERK corresponds to ERK1 and ERK2, respectively. Phosphorylated ERK1 was almost undetectable in T cells stimulated with anti-CD3 antibody. The graphs demonstrate the amount of phosphorylated ERK in 5min stimulated cells with or without morphine pretreatment. Phosphorylated ERK levels are normalized to each total ERK level and expressed as percentages of the CD3-stimulated cells without morphine pretreatment. Data are expressed as means \pm standard deviations from 5 separate experiments. pERK, phosphorylated ERK; tERK, total ERK. * * $\mathrm{P}<0.05$ compared with the CD3-stimulated cells without morphine pretreatment.

Fig. 2. Effect of morphine on ERK phosphorylation in Jurkat T cells stimulated with PMA/Io. (A) Jurkat T cells were incubated in the absence or presence of morphine (100 $\mu \mathrm{M}$ ) for $24 \mathrm{~h}$ and thereafter stimulated with PMA/Io for indicated times. (B) Jurkat T cells were incubated with indicated concentration of morphine for $24 \mathrm{~h}$ and followed by stimulation with PMA/Io for 5 min. Phosphorylated ERK and total ERK were detected by immunoblot analysis. The graph demonstrates the amount of phosphorylated ERK in PMA/Io-stimulated cells after pretreatment with different concentrations of morphine. Phosphorylated ERK 
levels are normalized to each total ERK level and expressed as percentages of the PMA/Iostimulated cells without morphine pretreatment. Data are expressed as means \pm standard deviations from 5 separate experiments. pERK, phosphorylated ERK; tERK, total ERK. * , $\mathrm{P}<0.05$ compared with the PMA/Io-stimulated cells without morphine pretreatment.

Fig. 3. Morphine itself does not induce ERK phosphorylation in Jurkat T cells. Jurkat T cells were incubated with morphine $(100 \mu \mathrm{M})$ for indicated times, and cell extracts were subjected to immunoblot analysis for ERK phosphorylation. Extract from Jurkat T cells stimulated with PMA/Io for 5 min was used for positive control. pERK, phosphorylated ERK; tERK, total ERK.

Fig. 4. Opioid receptors are unlikely to mediate the effect of morphine on ERK phosphorylation in activated T cells. (A) Jurkat T cells were incubated with indicated concentrations of morphine and naloxone for $24 \mathrm{~h}$, and thereafter stimulated with PMA/Io for 5 min. Phosphorylated ERK levels are normalized to each total ERK level and expressed as percentages of the PMA/Io-stimulated cells without morphine pretreatment. Data are expressed as means \pm standard deviations from 5 separate experiments. (B) RT-PCR analysis of total RNA from Jurkat T cells (lane b) and human placenta total RNA (lane c, positive control). Lane a is $1 \mathrm{~kb}$ DNA Ladder (Promega, Madison, WI). (C) Jurkat T cells were incubated in the absence or presence of U50,488 for $24 \mathrm{~h}$, and thereafter stimulated with PMA/Io for 5 min. Phosphorylated ERK levels are normalized to each total ERK level and expressed as percentages of the PMA/Io-stimulated cells without morphine pretreatment. 
Data are expressed as means \pm standard deviations from 5 separate experiments. pERK, phosphorylated ERK; tERK, total ERK. *, $\mathrm{P}<0.05$ compared with the PMA/Io-stimulated cells without morphine pretreatment. n.s., no significant difference.

Fig. 5. Effect of morphine on I $\kappa \mathrm{B} \alpha$ phosphorylaion and IL-2 expression in stimulated Jurkat T cells. (A) Jurkat $\mathrm{T}$ cells were incubated in the absence and presence of morphine (100 $\mu \mathrm{M})$ for $24 \mathrm{~h}$ and stimulated with PMA/Io for $5 \mathrm{~min}$. Phosphorylated $\mathrm{I} \kappa \mathrm{B} \alpha$ and $\beta$-actin in the cell extract were detected by immunoblot analysis. Phosphorylated I $\mathrm{B} \alpha \alpha$ levels are normalized to each $\beta$-actin level and expressed as percentages of the PMA/Io-stimulated cells without morphine pretreatment. Data are expressed as means \pm standard deviations from 5 separate experiments. (B, C) Jurkat T cells were incubated with indicated concentration of morphine and naloxone for $24 \mathrm{~h}$, and stimulated with PMA/Io for $4 \mathrm{~h}$. Total RNA was subjected to quantitative real-time RT-PCR to determine IL-2 and GAPDH mRNA levels. IL-2 mRNA level was normalized to each GAPDH mRNA level. IL-2 mRNA levels are expressed as percentages of the PMA/Io-stimulated cells without morphine pretreatment. Data are expressed as means \pm standard deviations from 5 separate experiments. $\quad$ pI $\kappa \alpha$,

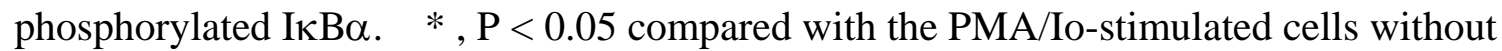
morphine pretreatment.

Fig. 6. Pathways leading to ERK and NF- $\kappa \mathrm{B}$ activation following TCR stimulation. The figure schematically depicts pathways by which TCR stimulation can lead to ERK and NF- $\kappa \mathrm{B}$ activation. ERK and NF- $\kappa \mathrm{B}$ have a common upstream signaling pathway involving DAG. 
Activation of PKC $\theta$ by DAG results in activation of an IאB kinase complex (IKK), phosphorylation and degradation of $\mathrm{I} \kappa \mathrm{B} \alpha$, and NF- $\kappa \mathrm{B}$ activation. Activation of ERK is achieved through two different pathways: a pathway through Grb2 and SOS and DAG-PKCRasGRP pathway. 
Fig. 1

A

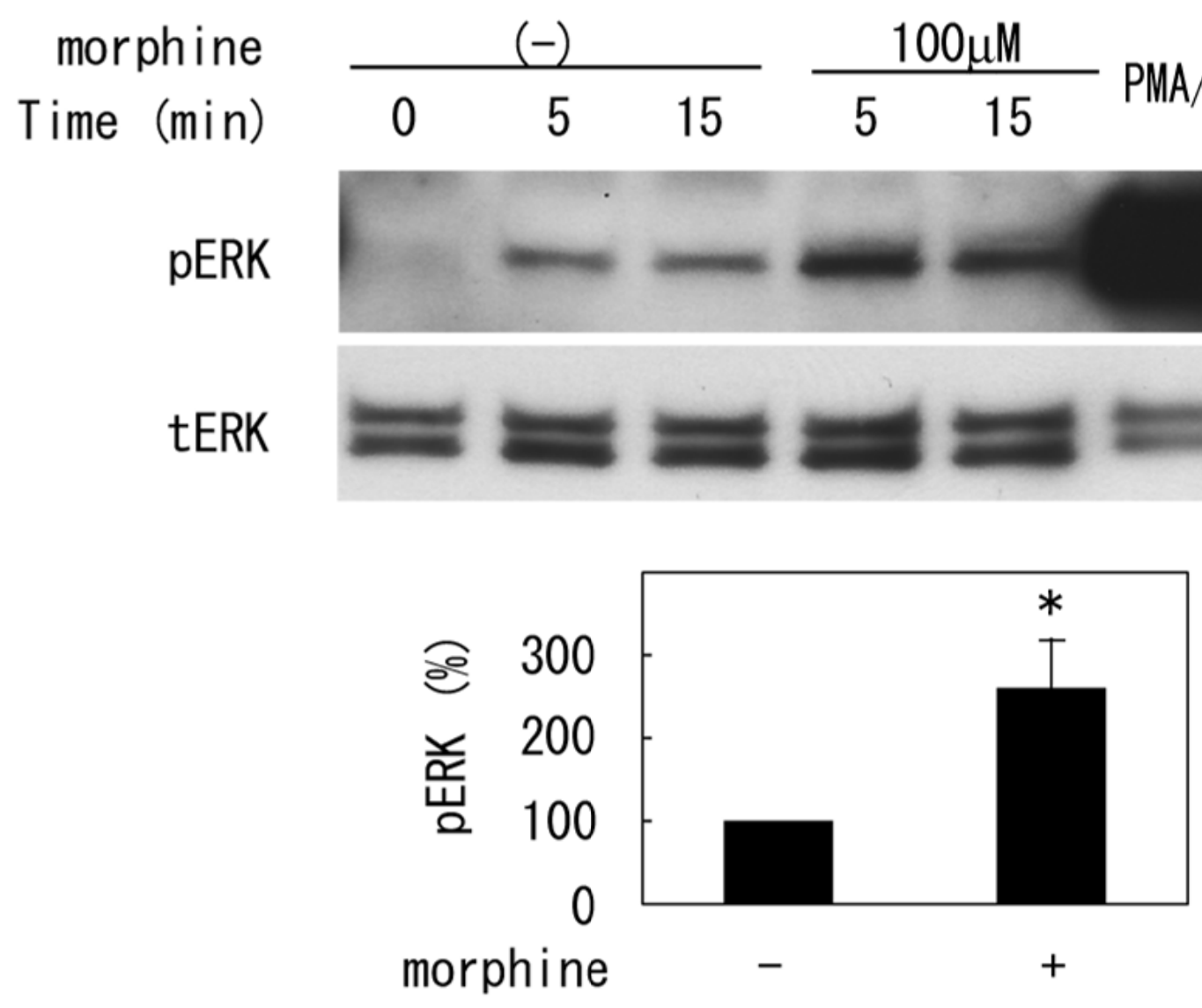

B morphine

Time (min)

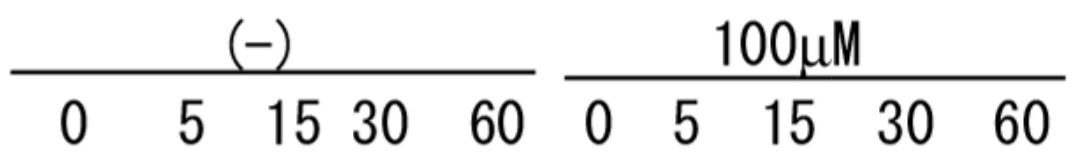

pERK

tERK

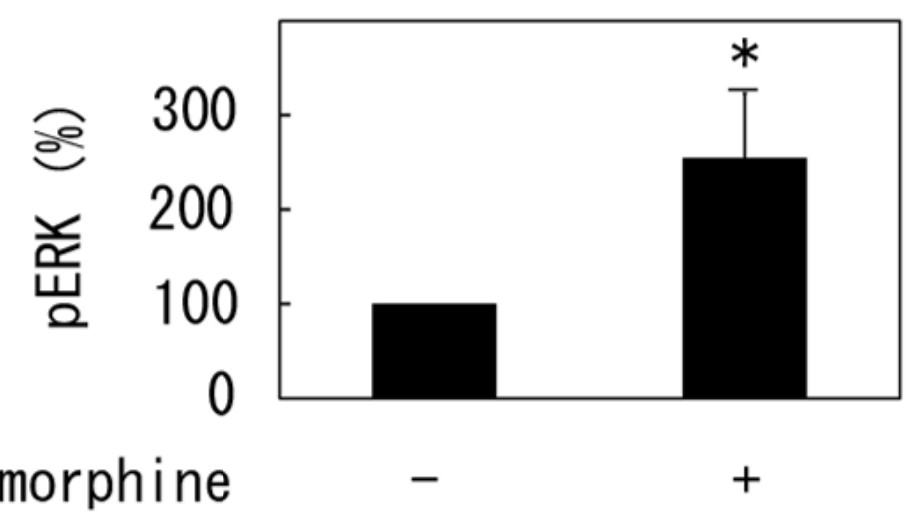


Fig. 2

A

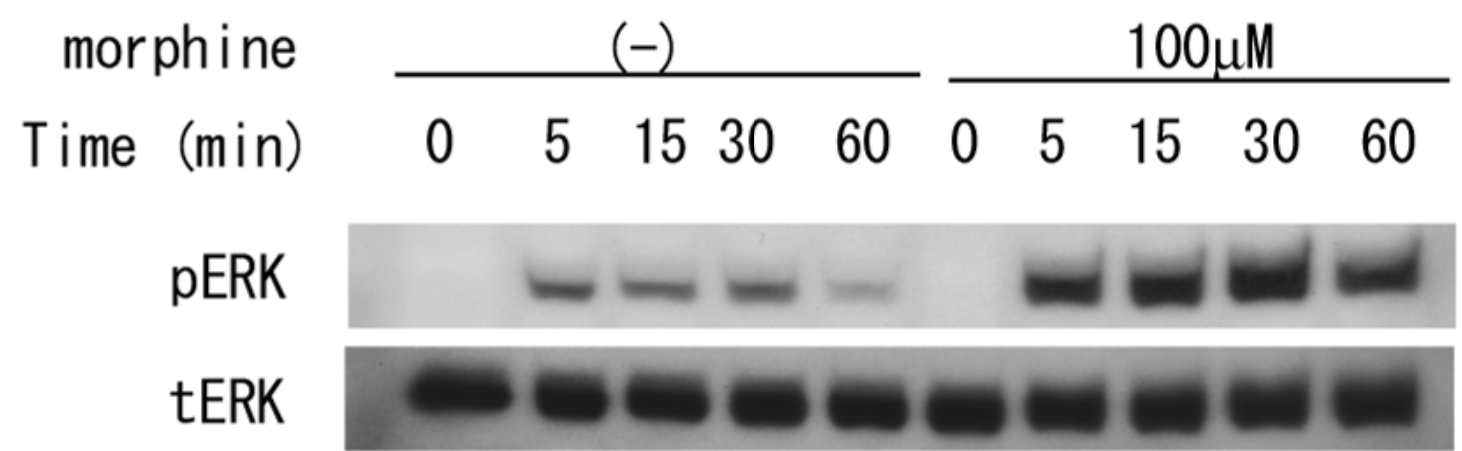

B

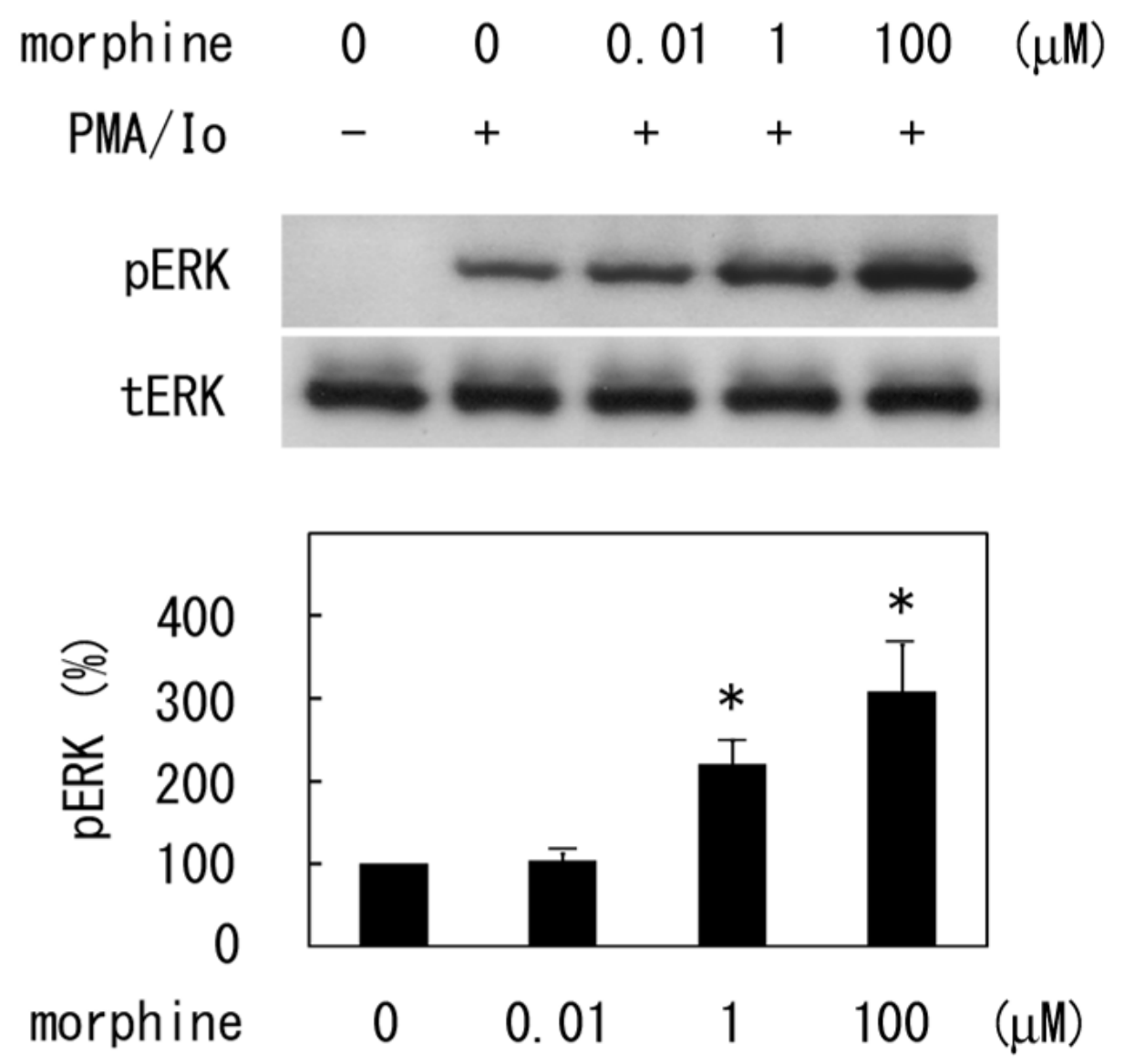


Fig. 3

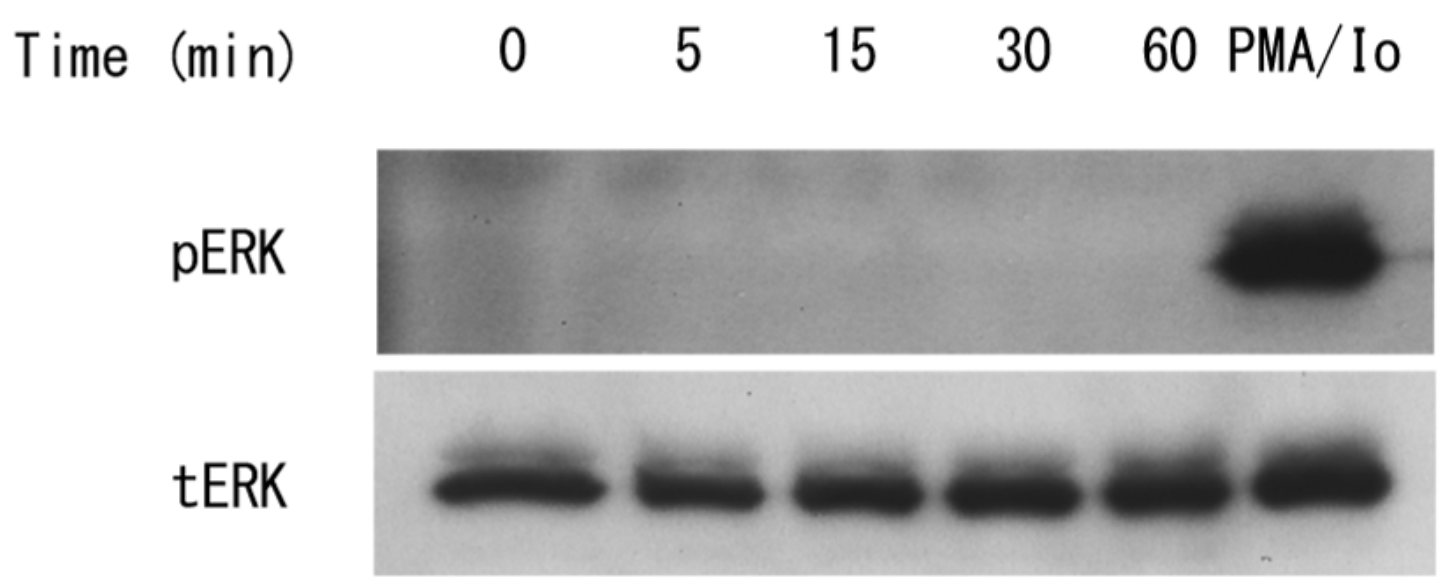


Fig. 4

$\begin{array}{ccccccc}\text { A morphine } & 0 & 0 & 1 & 1 & (\mu \mathrm{M}) \\ \text { naloxone } & 0 & 0 & 0 & 10 & (\mu \mathrm{M}) \\ \text { PMA/Io } & - & + & + & + & \\ & & & & & \\ \text { pERK } & & & & & \end{array}$

tERK

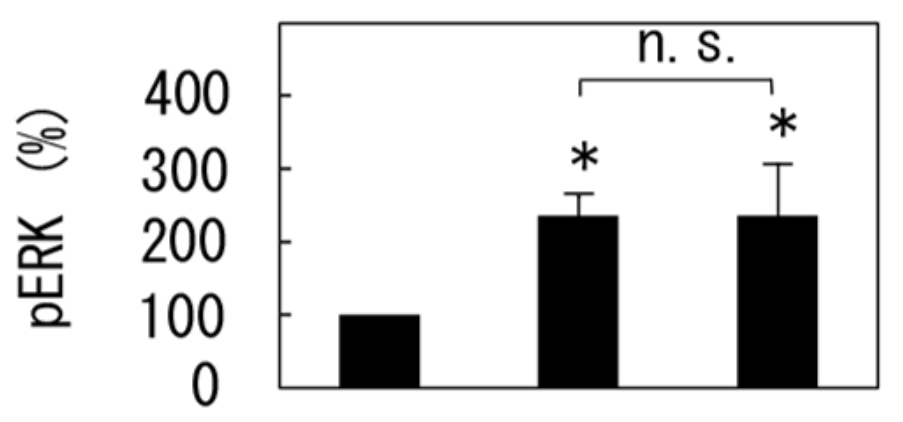

morphine 0

naloxone 0

B

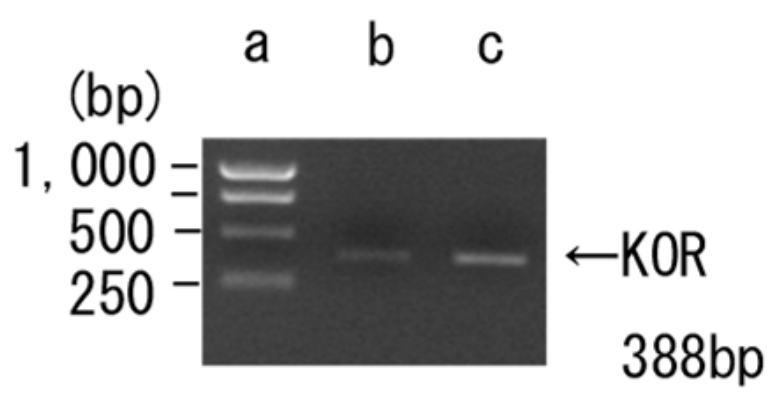

C

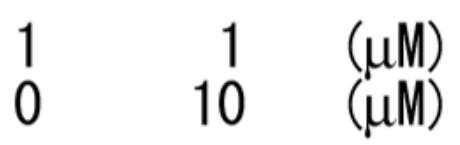

U50, $488 \quad-\quad-\quad+$

$\mathrm{PMA} / \mathrm{Io}-++$

pERK

tERK
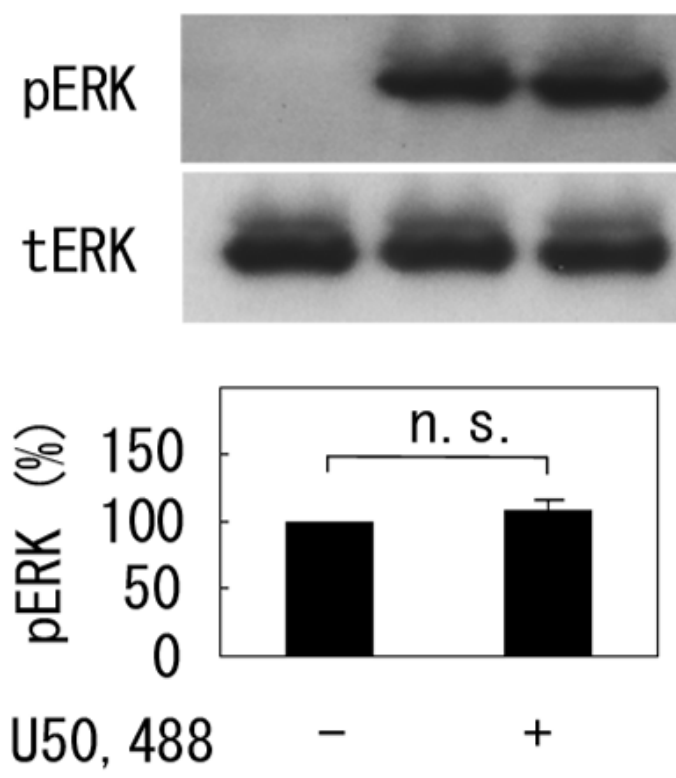
Fig. 5

A
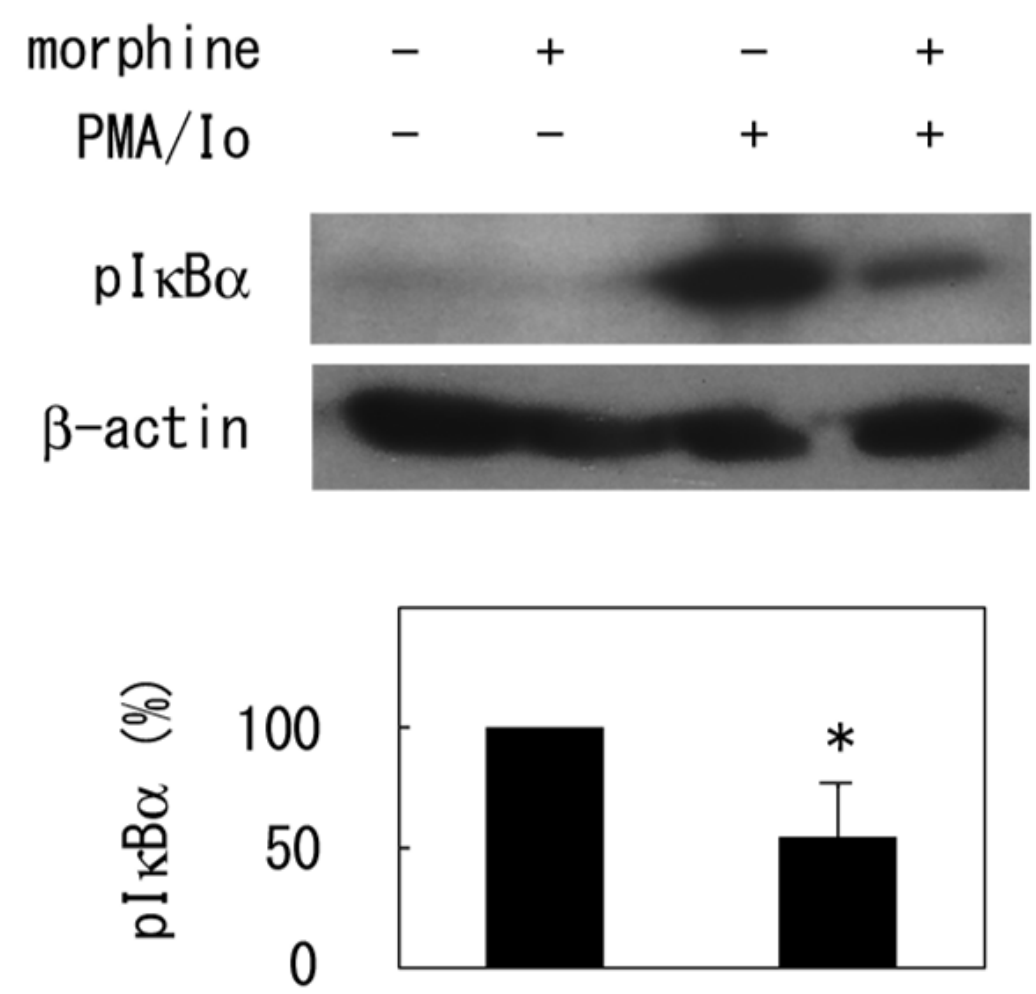

morphine

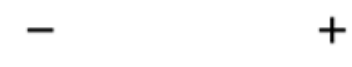

B

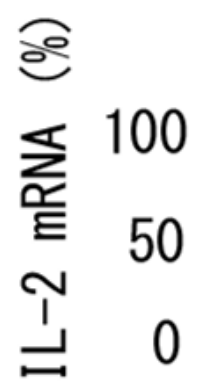

morphine 0 $(\mu \mathrm{M})$

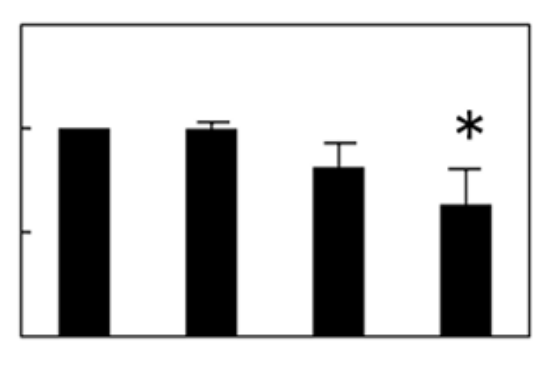
$0.01 \quad 1 \quad 100$
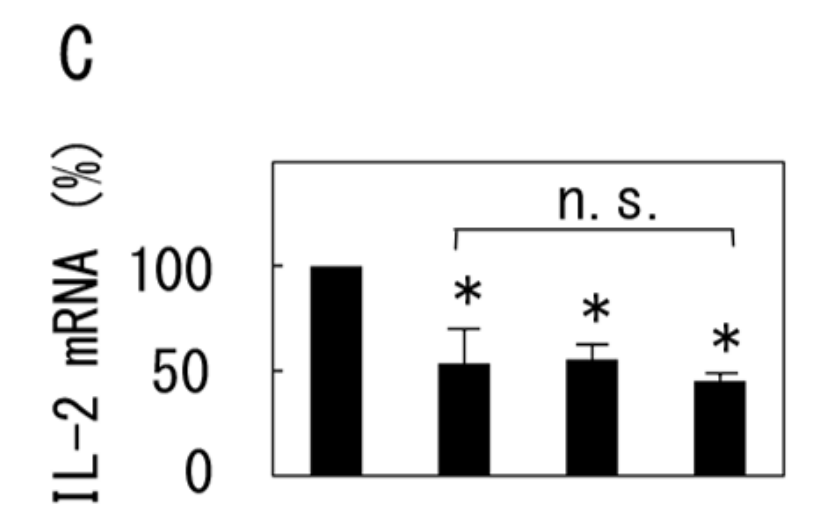

$\begin{array}{lllll}\text { morphine } & 0 & 100 & 100 & 100\end{array}$ $(\mu \mathrm{M})$ naloxone $\quad \begin{array}{llll}0 & 0 & 100 & 200\end{array}$ $(\mu \mathrm{M})$ 
Fig. 6

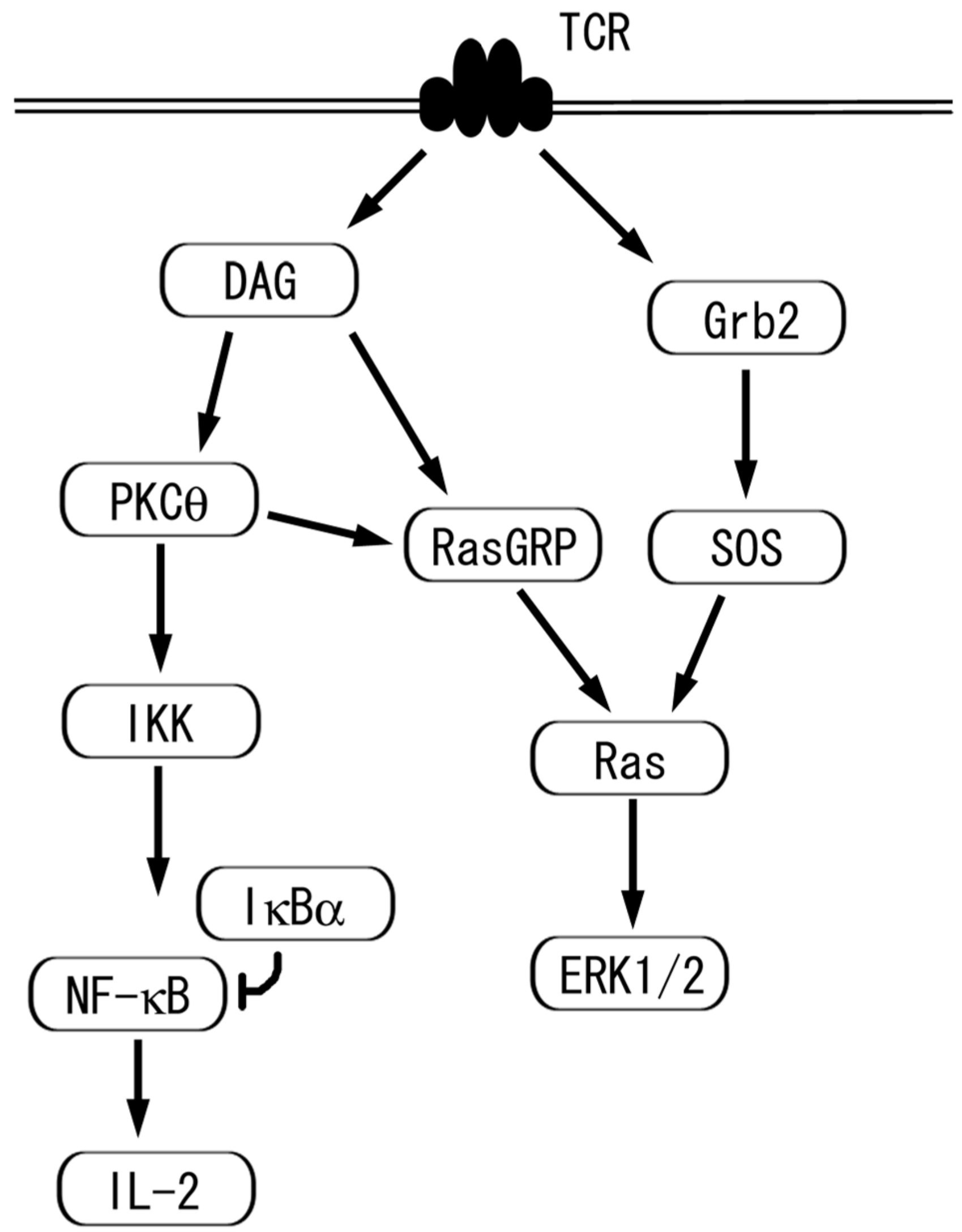

